\title{
Software-based simulation for preprocedural assessment of braided stent sizing: a validation study
}

\author{
Krishna Chaitanya Joshi, MBBS, MS, MCh, ${ }^{1}$ Ignacio Larrabide, DSc, ${ }^{2}$ Ahmed Saied, MD, ${ }^{3}$ \\ Nada Elsaid, MD, ${ }^{1}$ Hector Fernandez, BS, ${ }^{4}$ and Demetrius K. Lopes, MD ${ }^{1}$ \\ 'Department of Neurosurgery, Rush Medical Center, Chicago, Illinois; ${ }^{2}$ Pladema, CONICET, UNICEN, Tandil, Argentina; \\ ${ }^{3}$ Department of Neurology, Mansoura University, Mansoura, Egypt; and ${ }^{4}$ Galgo Medical SL, Barcelona, Spain
}

\begin{abstract}
OBJECTIVE The authors sought to validate the use of a software-based simulation for preassessment of braided selfexpanding stents in the treatment of wide-necked intracranial aneurysms.

METHODS This was a retrospective, observational, single-center study of 13 unruptured and ruptured intracranial aneurysms treated with braided self-expanding stents. Pre- and postprocedural angiographic studies were analyzed. ANKYRAS software was used to compare the following 3 variables: the manufacturer-given nominal length (NL), softwarecalculated simulated length (SL), and the actual measured length (ML) of the stent. Appropriate statistical methods were used to draw correlations among the 3 lengths.
\end{abstract}

RESULTS In this study, data obtained in 13 patients treated with braided self-expanding stents were analyzed. Data for the 3 lengths were collected for all patients. Error discrepancy was calculated by mean squared error (NL to ML -22.2 ; $\mathrm{SL}$ to $\mathrm{ML}-6.14, \mathrm{p}<0.05)$, mean absolute error (NL to $\mathrm{ML} 3.88$; $\mathrm{SL}$ to $\mathrm{ML}-1.84, \mathrm{p}<0.05$ ), and mean error (NL to $\mathrm{ML}$ -3.81 ; SL to $M L-1.22, p<0.05)$.

CONCLUSIONS The ML was usually less than the NL given by the manufacturer, indicating significant change in length in most cases. Computational software-based simulation for preassessment of the braided self-expanding stents is a safe and effective way for accurately calculating the change in length to aid in choosing the right-sized stent for optimal placement in complex intracranial vasculature.

https://thejns.org/doi/abs/10.3171/2018.5.JNS18976

KEYWORDS braided stents; software simulation; aneurysm; vascular disorders

$\mathrm{E}$ NDOVASCULAR stent-assisted coiling is used for aneurysm neck protection in wide-necked complex aneurysms. These type of stents, used for bridging the neck, are rapidly evolving in terms of stent design and delivery systems. Newer stents like the low-profile visualized intraluminal support (LVIS; MicroVention-Terumo) device have been successfully and safely used to treat wide-necked and complex aneurysms. ${ }^{6,8,20}$ Like all braided self-expanding stents, LVIS stents foreshorten when deployed, which is a factor of the size of stent used and parent vessel diameter. The stent sizing is usually done based on the diameter of the distal and proximal parent artery. There is no accurate way of predicting the exact amount of foreshortening or change in length before the deployment of the stent. We used a computer software-based simulation (ANKYRAS [Galgo Medical SL]) to predict the change in length, which might help us to choose the correct stent size.

Computer-based advanced design modeling tools for predicting stent size have been used before..$^{22}$ Most of the software available is for the deployment of flow diverters and has never been used for braided self-expanding stents like LVIS devices, which have a totally different design from their predecessors. We present quantitative data of preassessment of stent size using ANKYRAS software and the actual stent size after deployment.

\section{Methods}

A total of 13 consecutive patients treated with LVIS Jr. were enrolled in this study. The study is retrospective, and the selection of the treatment and the device was made by

ABBREVIATIONS BDF = braided device foreshortening; LVIS = low-profile visualized intraluminal support; $M A E=$ mean absolute error; $M E=$ mean error; $M S E=$ mean squared error; 3DRA $=3 \mathrm{D}$ rotational angiography.

SUBMITTED April 9, 2018. ACCEPTED May 29, 2018.

INCLUDE WHEN CITING Published online November 9, 2018; DOI: 10.3171/2018.5.JNS18976. 
the operating physician at the time of the intervention in all cases. IRB approval was not required for the study as it was a retrospective review.

\section{Image Acquisition}

Pretreatment anatomical models of the vasculature were generated from 3D rotational angiography (3DRA) images obtained using an AXIOM Artis (Siemens Medical Solutions; $n=17$ ). Voxel sizes of 3DRA images ranged from $0.208 \times 0.208 \times 0.208 \mathrm{~mm}$ to $0.378 \times 0.378 \times 0.378$ $\mathrm{mm}$.

Posttreatment 2D sequences were used to localize the proximal and distal ends of the stent in the anatomy and to measure the length of the stent after implantation. The angiographic sequences had a 2D spatial resolution of 0.200 $\times 0.200 \mathrm{~mm}$. Both 3D pretreatment and 2D posttreatment images were obtained during the same intervention.

\section{D Anatomical Model}

Images were segmented using a threshold-based segmentation method. In each case, the threshold value was chosen by an expert in neurovascular angiography to best fit the patient's anatomy depending on the amount of contrast observed and image quality. When selecting the threshold value, both the treated vessel and aneurysm were considered the first priority for the reconstruction. Smaller and branching vessels were considered a second priority. Four of the 13 cases (31\%) required additional mesh editing and postprocessing due to poor contrast dilution or suboptimal image quality. The mesh editing process is performed on the surface representation (triangular mesh) of the anatomy and entails removing triangles, closing holes, and smoothing the mesh with the aim of removing artifacts generated by low-contrast density or the presence of coils. This process is identical to that used for the generation of anatomical models in computational flow dynamics analysis. ${ }^{4}$ 3D models were then visually validated by expert interventional neuroradiologists. The centerline was computed for the treated branch, and vascular morphology descriptors were computed along the vessel. ${ }^{19}$

\section{Stent Length Measurement}

The length of the implanted stent inside the patient was measured from posttreatment $2 \mathrm{D}$ angiographic sequences (Fig. 1 upper). The 3D model obtained from the pretreatment 3DRA images was used to generate a centerline. The 3D model was manually aligned (registered) to the same point of view as the $2 \mathrm{D}$ images were acquired. The contrast phase of the 2D sequence was used to determine the anatomical location and orientation for a precise alignment between 3D pretreatment model and 2D posttreatment image sequence. ${ }^{5}$ Finally, the distal and proximal
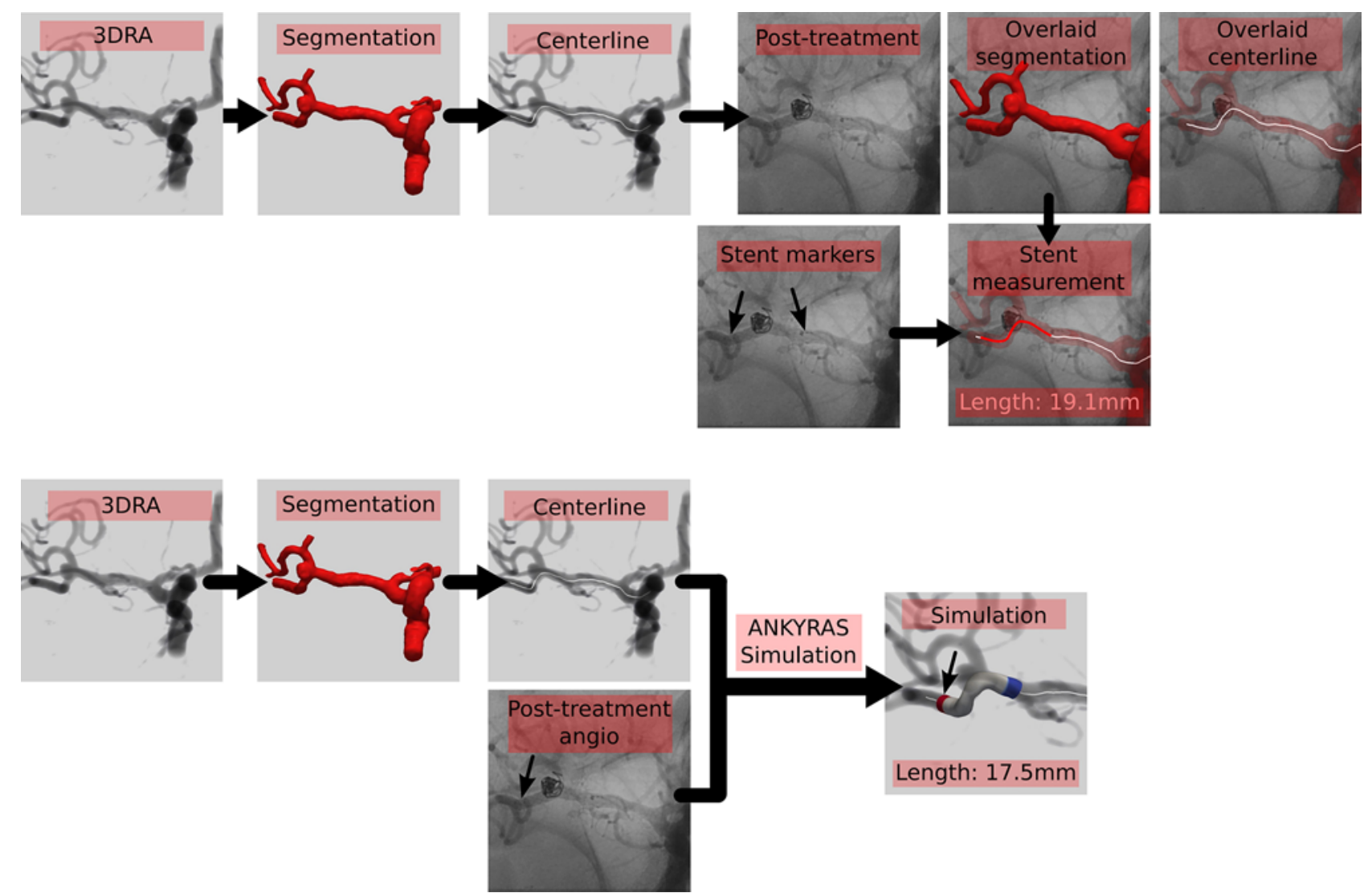

FIG. 1. Upper: Steps for measuring the actual length of the stent based on pre- and postprocedural 3D angiograms. Lower: Steps for simulating the stent and obtaining its length based on the preprocedural angiographic images. Figure is available in color online only. 
markers of the device were identified on the 2D image and projected on the centerline. The length of the device was calculated as the distance along the centerline between the distal and proximal ends. When biplane acquisitions were available, the view where the endpoints were more clearly visible was chosen.

\section{Simulation of Stent Length}

Braided stent length was simulated using the braided device foreshortening (BDF) algorithm (Fig. 1 lower). This method requires a 3D model of the vessel from which the centerline is computed and the local morphology of the vessel is characterized. The computational models used to simulate each device are based on numbers of wires of the stent and the length at two different diameters, which was available from device manufacturer specifications. This information was used to parameterize the simulation following the procedure described by Fernandez et al. ${ }^{5}$ Local morphology is associated with the vessel crosssection (perpendicular to its centerline), and it is described by the diameter of the maximum inscribed sphere, perimeter of the vessel, and cross-sectional area. The centerline of these 3D meshes and the local morphology descriptors along the centerline were obtained within ANKYRAS. ${ }^{19}$

The centerline was divided into segments sufficiently small so that local morphological descriptors can be considered constant along each segment. The distal end position of the simulated stent was matched to the position observed on the 2D angiographic sequences and the proximal one was obtained by running the BDF algorithm. The BDF algorithm is described in detail by Fernandez et al. ${ }^{5}$ The final length of the braided stent is the distance between the distal end and the proximal end of the simulated braided stent along the centerline. The BDF algorithm is embedded in ANKYRAS software, which allows performing the full image processing and morphology quantification workflow in a single software package.

\section{Error Assessment}

The simulation was assessed using an error measure. The error between both the nominal length and the simulated length was compared to the length measured from the posttreatment images using the following criteria:

$$
\operatorname{MSE}\left[\mathrm{mm}^{2}\right](\mathrm{S}, \mathrm{M})=\text { mean }\left((\mathrm{S}-\mathrm{M})^{2}\right)
$$

The mean squared error (MSE) accounts for the squared differences between measured and approximated stent length.

$$
\operatorname{MAE}[\mathrm{mm}](\mathrm{S}, \mathrm{M})=\text { mean }|\mathrm{S}-\mathrm{M}|
$$

The mean absolute error (MAE) quantifies the absolute differences between measured and approximated stent length.

$$
\mathrm{ME}[\mathrm{mm}](\mathrm{S}, \mathrm{M})=\text { mean }(\mathrm{S}-\mathrm{M})
$$

The mean error (ME) represents the mean difference between measured and approximated stent lengths. In the above, $\mathrm{S}$ is either the nominal length or the simulated

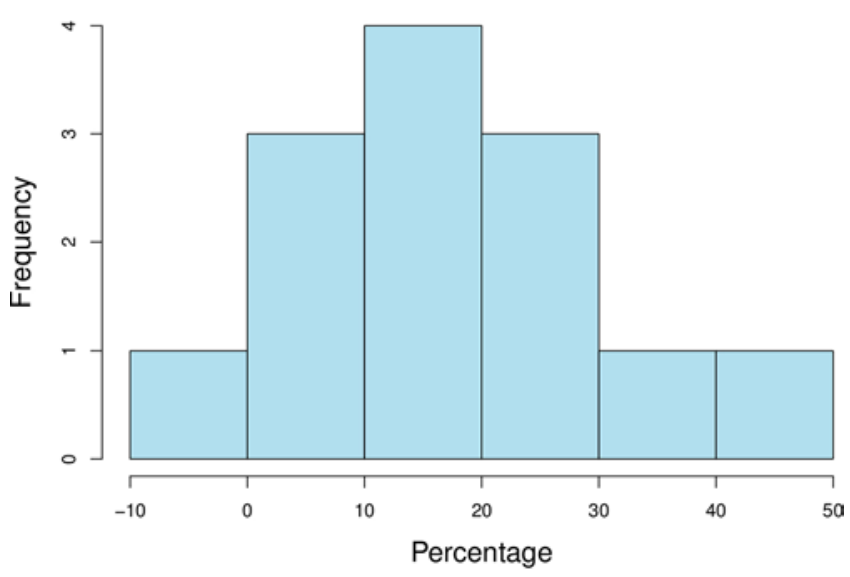

FIG. 2. Histogram of the distribution of length change after placement of the device. The frequency is computed for the relative device length change compared to the nominal ((measured length - nominal length)/ nominal length $\times 100 \%$ ). Figure is available in color online only.

length, and $\mathrm{M}$ is the length measured from the posttreatment images.

\section{Results}

Pretreatment and posttreatment angiographic data of 13 patients with intracranial aneurysms treated with LVIS stents were retrospectively analyzed. Three important parameters were documented: 1) nominal length of the stent, that is, the length of the stent as stated by the manufacturer; 2) simulated length, that is, the length of the stent as measured by using the software; and 3) measured length, that is, the length of the stent as measured after deployment. Figure 2 shows the distribution of length changes observed between nominal and measured lengths in the cases studied. Changes of up to $50 \%$ with respect to nominal length in stent length occurred, with a mean change of $20 \%$. It was also observed that changes could be negative, indicating that the final length could be smaller than the nominal length.

The error discrepancy between these measurements was calculated using three standard measures of error (Table 1). The MSE or mean squared deviation (MSD) of an estimator (of a procedure for estimating an unobserved quantity) measures the average of the squares of the errors or deviations - that is, the difference between the estimator and what is estimated. The MSE is a risk function, corresponding to the expected value of the squared error loss or quadratic loss. The difference occurs because of variations in technique of the intervening physician or because the estimator does not account for information that could produce a more accurate estimate. The MSE between the

TABLE 1. Discrepancy in the degree of error between simulated and nominal lengths: the measured length

\begin{tabular}{lrrr}
\hline \multicolumn{1}{c}{ Length } & MSE & MAE & ME \\
\hline Nominal to measured & 22.20 & 3.88 & -3.81 \\
\hline Simulated to measured & 6.14 & 1.84 & -1.22 \\
\hline
\end{tabular}




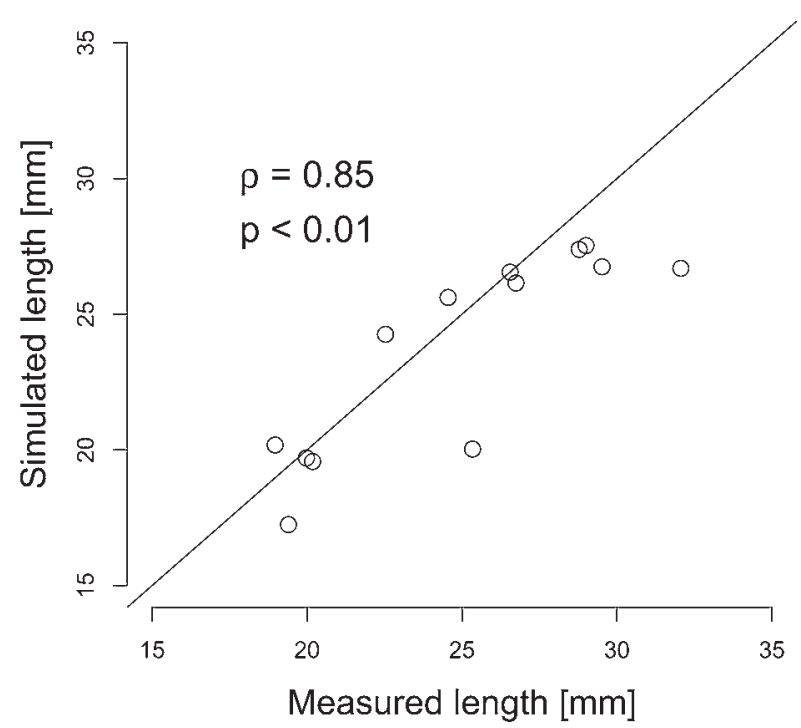

FIG. 3. Scatterplot comparing simulated and measured lengths. Pearson's correlation rho and corresponding $p$ value are also indicated.

nominal and measured was $22.2 \mathrm{~mm}$ and between the simulated and measured was $6.14 \mathrm{~mm}$. The second tool we used was MAE, which is an average of the absolute errors. The MAE uses the same scale as the data being measured, and it ignores whether it is an under- or over-prediction. The MAE between nominal and measured values was $3.88 \mathrm{~mm}$ and between simulated and measured lengths was $1.84 \mathrm{~mm}$. These values were charted on a scatterplot, which shows a positive correlation between nominal and measured lengths ( $r h o=0.77, p<0.01$ ), as well as between simulated and measured values (rho $=0.85, \mathrm{p}<0.01$, Fig. 3 ). The third measure used was ME, the average of all the errors in the set. The ME takes into account if there was under- or over-prediction. The ME between nominal and measured lengths was $-3.81 \mathrm{~mm}$ and that between simulated and measured lengths was $-1.22 \mathrm{~mm}$. It also means the measured length was usually less than the nominal length given by the manufacturer, indicating significant foreshortening in most cases. The Wilcoxon signed-rank paired test showed that nominal and simulated lengths were significantly different $(\mathrm{p}<0.01)$, which, supported by the error measures, indicates that simulation is more accurate and close to the actual length of the implanted device than the nominal size. These values were charted on a Bland-Altman plot to show the mean difference in length between the measured and simulated lengths (Fig. 4).

Accuracy in measuring the length of the device from $2 \mathrm{D}$ images after alignment with the 3D model was assessed. This assessment was performed on data sets in which more than one posttreatment 2D viewpoint was available. For each $2 \mathrm{D}$ viewpoint, the $3 \mathrm{D}$ model was registered to that viewpoint and stent length was measured (Fig. 5). The intraobservation (between measurements for the same stent) standard deviation was computed, resulting in the following: a maximum SD of $1.27 \mathrm{~mm}$, a minimum SD of 0.28 $\mathrm{mm}$, and mean SD of $0.62 \mathrm{~mm}$. This means that measuring the same stent from different viewing positions introduces an error, which was $0.62 \mathrm{~mm}$ on average.

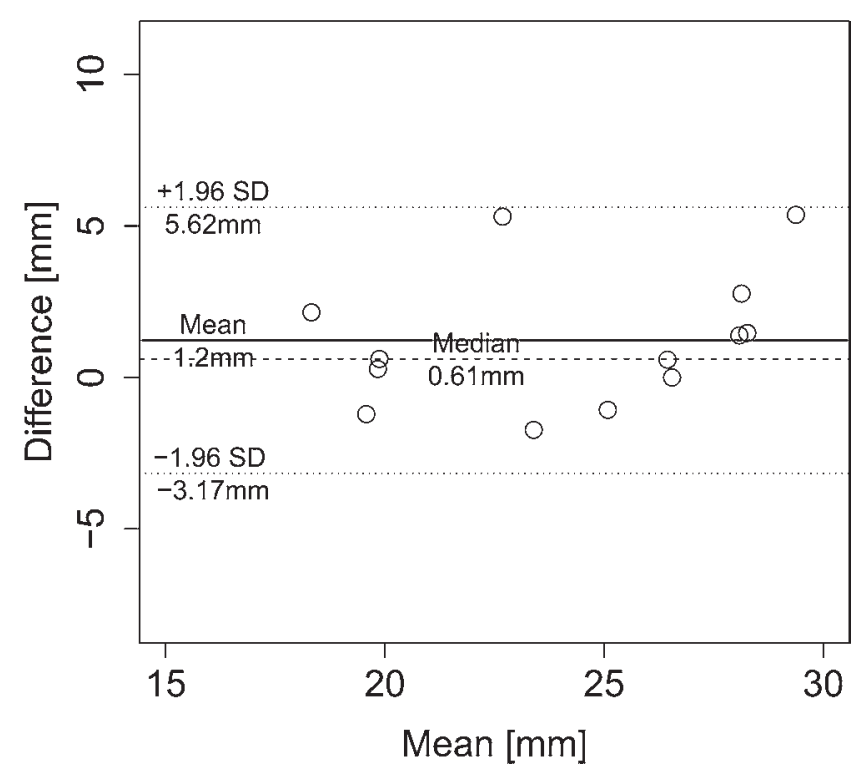

FIG. 4. Bland-Altman plot showing differences in ME between simulated length and measured length. The mean difference is $1.2 \mathrm{~mm}$ (median $0.61 \mathrm{~mm})$.

Pearson's correlation analysis showed a rho of $0.857(\mathrm{p}$ $<0.001)$ when comparing measured to simulated lengths. However, the same test comparing measured to nominal lengths rendered a rho of $0.776(\mathrm{p}<0.001)$. A dependent 2-group Wilcoxon signed-rank test (paired) was performed for the residuals (nominal length to the measured length and simulated to measured length) and $p=0.0004883$ was found. This means that the mean of the residuals cannot be assumed to be equal to 0 . Furthermore, the residual comparing the nominal to the measured length $(-3.8 \mathrm{~mm})$ was found to be significantly larger than the residual comparing the simulated to the measured length $(-1.2 \mathrm{~mm})$. This means that the average difference between the nominal length and the measured length was $-3.8 \mathrm{~mm}$ (i.e., the nominal is $3.8 \mathrm{~mm}$ shorter than the measured length). This was greater than the average difference between the simulated and the measured lengths, which was $-1.2 \mathrm{~mm}$ (i.e., the simulated was $1.2 \mathrm{~mm}$ shorter than the measured length).

\section{Discussion}

The new-generation braided self-expanding stents like the LVIS device are used for endovascular treatment of wide-necked intracranial aneurysms. They have the advantage of being low profile, are easily deliverable through a smaller microcatheter system, and can be resheathed, making them an ideal choice for treatment of complex wide-necked aneurysms.

Braided stents have the advantage of fitting into highly tortuous vessels. However, most have a degree of foreshortening that is a very critical factor to consider before deployment. The degree of foreshortening is generally related to the size of parent vessel and to the size of stent.

Nominal length is the length of the stent that is described by the manufacturer as the possible length of the 


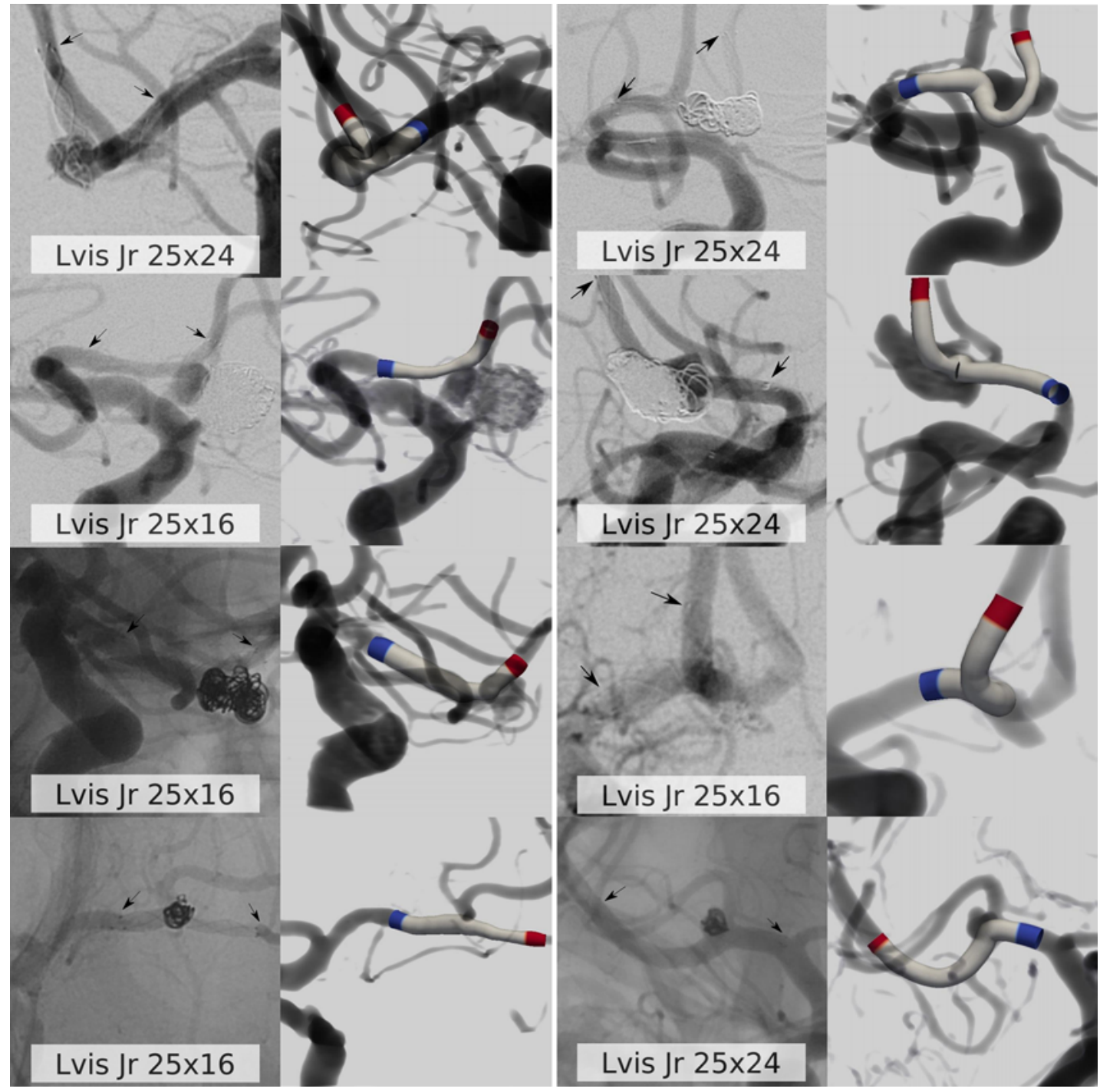

FIG. 5. Placement of the simulated stent in various aneurysms with complex anatomy based on the preprocedural angiographic images. An implanted stent is indicated next to each angiogram. Red and blue highlights on the stent indicate the flared ends. Figure is available in color online only.

stent that will be in vitro as a factor of the size of the parent vessel. It does not, however, consider the fact that the size of the parent vessel may not be uniform, that it differs around the curves, and also that it is usually tapered along the length of the artery. This is why the nominal length is not a reliable measurement.

To calculate the possible length of the stent accurately, we used the 3D angiographic image of the artery that is to be stented and used ANKYRAS software to calculate the simulated length. The simulated length takes into account the complex shape of the artery and possible tapering and variable diameter around the curves. The simulated length was found to be a more accurate predictor of the actual length when compared to the company-provided nominal length. The simulation can also help the interventionist in accurately planning and choosing the size of the stent. Preprocedural calculation of length and positioning can be simulated to safely land on the desired proximal land- ing zone covering or avoiding smaller branching vessels. Also, it can help avoid tortuous and/or highly curved regions. Similar studies done with other braided stents, such as the Derivo, Pipeline, P64, and Surpass, have shown that simulation can be very useful in stent placement. ${ }^{21}$ Suzuki et al. used a computational flow dynamics model when studying the various mechanical properties in braided stents in in vivo models. They found that the degree of change in length can be a factor of the mechanical property of the stents like the braiding angle, and it can vary among various stent designs. ${ }^{21}$

There are many methods of software-based simulation for stent placement in intracranial vessels. The first generation of computation simulation included the direct placement method, ${ }^{7,9}$ where a uniform stent tube was simply fitted into a parent vessel. However, these are not suitable for treatment planning due to a grossly unrealistic stent or braided stent geometry and poor stent-wall apposition. 
Finite element method-based techniques, ${ }^{7,14,23}$ which more realistically simulate the mechanical processes in the deployment procedure, come at high computational costs that prohibit them from use in routine clinical treatment planning. Appanaboyina et al. ${ }^{1}$ described a methodology based on unstructured embedded grids for patient-specific modeling of stented cerebral aneurysms; they used a number of patient-specific models constructed from medical images, and they used different stent designs and treatment alternatives. Their results showed that these simulations provide useful and valuable information that can be used during the planning phase of endovascular stent interventions for the treatment of intracranial aneurysms. Larrabide et al. ${ }^{13}$ used the fast virtual stenting method, ${ }^{3}$ which provides an estimation of the configuration of intracranial stents when released in realistic geometries. This method was based on constrained simplex deformable models. The constraints are used to account for the stent design. The performance of their proposed methodology was contrasted with real stents released in a silicone phantom. The results of their study showed that use of the fast virtual stenting methodology in the clinical environment could provide additional information to clinicians before the treatment to choose the therapy that best fits the patient.

The intracranial vasculature differs from that of in vivo models used in most previous studies using computational models. In vitro vessels are complex and have patientspecific geometries. In the previous expansion-based approaches, a cylindrical surface was geometrically inflated in the parent vessel, where the surface crossed the vessel wall in patient-specific geometries, thus requiring a negative force to bring it back to within the vessel. ${ }^{2}$ Although such techniques have been successfully used to prove different hypotheses and predict the hemodynamic effect of endovascular treatment of intracranial aneurysms, they have a very specific purpose, related to the modeling of computational fluid dynamics simulations. ${ }^{10-12,15-18}$

Software simulation can also further help in accurately finding the landing zone for the stent and can expand the feasibility of using braided devices when there is concern of crossing major bifurcations if the device is too long or falling into an aneurysm if the device is too short. None of the existing virtual stenting methods has been adopted clinically, and this is the first clinical study to validate the role of software-assisted simulation in stent-assisted treatment of intracranial aneurysms.

\section{Conclusions}

The new generation of low-profile, self-expanding, braided stents is associated with significant change in length in vivo. This could be a serious problem and could potentially cause stent misplacement. Several softwarebased tools are being developed to counter this problem and help clinicians in the decision-making and treatment planning. These tools help to produce accurate and clinically meaningful results, with a high level of usability and automation at low computational costs. Software simulation can allow endovascular devices to be deployed virtually inside patient-specific vascular geometries. It can allow safe comparison of different devices before treatment to enhance the selection of the device.

\section{References}

1. Appanaboyina S, Mut F, Löhner R, Putman C, Cebral J: Simulation of intracranial aneurysm stenting: techniques and challenges. Comput Methods Appl Mech Eng 198:35673582,2009

2. Bernardini A, Larrabide I, Morales HG, Pennati G, Petrini L, Cito S, et al: Influence of different computational approaches for stent deployment on cerebral aneurysm haemodynamics. Interface Focus 1:338-348, 2011

3. Bernardini A, Larrabide I, Petrini L, Pennati G, Flore E, Kim $\mathrm{M}$, et al: Deployment of self-expandable stents in aneurysmatic cerebral vessels: comparison of different computational approaches for interventional planning. Comput Methods Biomech Biomed Engin 15:303-311, 2012

4. Cebral JR, Castro MA, Appanaboyina S, Putman CM, Millan D, Frangi AF: Efficient pipeline for image-based patient-specific analysis of cerebral aneurysm hemodynamics: technique and sensitivity. IEEE Trans Med Imaging 24:457-467, 2005

5. Fernandez H, Macho JM, Blasco J, Roman LS, Mailaender W, Serra L, et al: Computation of the change in length of a braided device when deployed in realistic vessel models. Int J CARS 10:1659-1665, 2015

6. Fiorella D, Arthur A, Boulos A, Diaz O, Jabbour P, Pride L, et al: Final results of the US humanitarian device exemption study of the low-profile visualized intraluminal support (LVIS) device. J Neurointerv Surg 8:894-897, 2016

7. Fu W, Gu Z, Meng X, Chu B, Qiao A: Numerical simulation of hemodynamics in stented internal carotid aneurysm based on patient-specific model. J Biomech 43:1337-1342, 2010

8. Iosif C, Piotin M, Saleme S, Barreau X, Sedat J, Chau Y, et al: Safety and effectiveness of the Low Profile Visualized Intraluminal Support (LVIS and LVIS Jr) devices in the endovascular treatment of intracranial aneurysms: results of the TRAIL multicenter observational study. J Neurointerv Surg 10:675-681, 2018

9. Kim M, Taulbee DB, Tremmel M, Meng H: Comparison of two stents in modifying cerebral aneurysm hemodynamics. Ann Biomed Eng 36:726-741, 2008

10. Larrabide I, Aguilar ML, Morales HG, Geers AJ, Kulcsár $\mathrm{Z}$, Rüfenacht D, et al: Intra-aneurysmal pressure and flow changes induced by flow diverters: relation to aneurysm size and shape. AJNR Am J Neuroradiol 34:816-822, 2013

11. Larrabide I, Geers AJ, Morales HG, Aguilar ML, Rüfenacht DA: Effect of aneurysm and ICA morphology on hemodynamics before and after flow diverter treatment. J Neurointerv Surg 7:272-280, 2015

12. Larrabide I, Geers AJ, Morales HG, Bijlenga P, Rüfenacht DA: Change in aneurysmal flow pulsatility after flow diverter treatment. Comput Med Imaging Graph 50:2-8, 2016

13. Larrabide I, Kim M, Augsburger L, Villa-Uriol MC, Rüfenacht D, Frangi AF: Fast virtual deployment of self-expandable stents: method and in vitro evaluation for intracranial aneurysmal stenting. Med Image Anal 16:721-730, 2012

14. Ma D, Xiang J, Choi H, Dumont TM, Natarajan SK, Siddiqui $\mathrm{AH}$, et al: Enhanced aneurysmal flow diversion using a dynamic push-pull technique: an experimental and modeling study. AJNR Am J Neuroradiol 35:1779-1785, 2014

15. Morales HG, Bonnefous O, Geers AJ, Brina O, Pereira VM, Spelle L, et al: Does arterial flow rate affect the assessment of flow-diverter stent performance? AJNR Am J Neuroradiol 37:2293-2298, 2016

16. Morales HG, Kim M, Vivas EE, Villa-Uriol MC, Larrabide I, Sola T, et al: How do coil configuration and packing density influence intra-aneurysmal hemodynamics? AJNR Am J Neuroradiol 32:1935-1941, 2011

17. Morales HG, Larrabide I, Geers AJ, Aguilar ML, Frangi AF: Newtonian and non-Newtonian blood flow in coiled cerebral aneurysms. J Biomech 46:2158-2164, 2013 
18. Ouared R, Larrabide I, Brina O, Bouillot P, Erceg G, Yilmaz $\mathrm{H}$, et al: Computational fluid dynamics analysis of flow reduction induced by flow-diverting stents in intracranial aneurysms: a patient-unspecific hemodynamics change perspective. J Neurointerv Surg 8:1288-1293, 2016

19. Piccinelli M, Veneziani A, Steinman DA, Remuzzi A, Antiga L: A framework for geometric analysis of vascular structures: application to cerebral aneurysms. IEEE Trans Med Imaging 28:1141-1155, 2009

20. Poncyljusz W, Biliński P, Safranow K, Baron J, Zbroszczyk M, Jaworski M, et al: The LVIS/LVIS Jr. stents in the treatment of wide-neck intracranial aneurysms: multicentre registry. J Neurointerv Surg 7:524-529, 2015

21. Suzuki T, Takao H, Fujimura S, Dahmani C, Ishibashi T, Mamori $\mathrm{H}$, et al: Selection of helical braided flow diverter stents based on hemodynamic performance and mechanical properties. J Neurointerv Surg 9:999-1005, 2017

22. Xiang J, Damiano RJ, Lin N, Snyder KV, Siddiqui AH, Levy EI, et al: High-fidelity virtual stenting: modeling of flow diverter deployment for hemodynamic characterization of complex intracranial aneurysms. J Neurosurg 123:832-840, 2015

23. Xiang J, Ma D, Snyder KV, Levy EI, Siddiqui AH, Meng H: Increasing flow diversion for cerebral aneurysm treatment using a single flow diverter. Neurosurgery 75:286-294, 2014

\section{Disclosures}

Dr. Larrabide has an ownership stake in Galgo Medical SL. Mr. Fernandez is a shareholder in and employee of Galgo Medical SL.

\section{Author Contributions}

Conception and design: Joshi, Larrabide, Lopes. Acquisition of data: Joshi, Larrabide, Elsaid. Analysis and interpretation of data: all authors. Drafting the article: Joshi. Critically revising the article: all authors. Reviewed submitted version of manuscript: Joshi, Larrabide, Saied, Elsaid, Fernandez, Lopes. Approved the final version of the manuscript on behalf of all authors: Joshi. Statistical analysis: Joshi, Larrabide. Administrative/technical/material support: Joshi, Lopes. Study supervision: Joshi, Lopes.

\section{Correspondence}

Krishna Chaitanya Joshi: Rush Medical Center, Chicago, IL. krishna_c_joshi@rush.edu. 